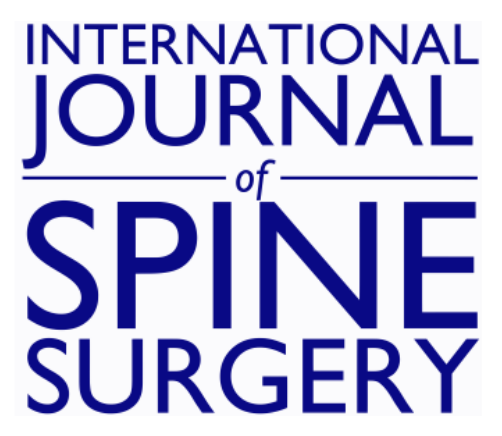

\title{
Facet Sparing Foraminal Decompression Using the Flexible Shaver Foraminotomy System: Nerve Safety, Pain Relief, and Patient Satisfaction
}

MORENIKEJI BURAIMOH, CHASE ANSOK, JACOB PAWLOSKI, EDWARD K. JUNG and STEPHEN BARTOL

Int J Spine Surg 2018, 12 (2) 92-97

doi: https://doi.org/10.14444/5015

http://ijssurgery.com/content/12/2/92

This information is current as of April 26, 2023.

Email Alerts Receive free email-alerts when new articles cite this article. Sign up at: http://ijssurgery.com/alerts 


\title{
Facet Sparing Foraminal Decompression Using the Flexible Shaver Foraminotomy System: Nerve Safety, Pain Relief, and Patient Satisfaction
}

\author{
MORENIKEJI BURAIMOH, MD ${ }^{1}$ CHASE ANSOK, MD,${ }^{1} \mathrm{JACOB}$ PAWLOSKI, BA, ${ }^{2}$ EDWARD K. JUNG, \\ MD, MS, ${ }^{1}$ STEPHEN BARTOL, MD, MBA ${ }^{1}$ \\ ${ }^{I}$ Department of Orthopaedics, Henry Ford Hospital, Detroit, Michigan, ${ }^{2}$ Wayne State University School of Medicine, Detroit, Michigan
}

\begin{abstract}
Background: A number of surgical options exist for decompressing lumbar foraminal stenosis. Flexible shaver foraminotomy is a recent addition to this armamentarium. While the foraminotomy device has been incorporated into clinical practice, the literature on its safety and efficacy remain limited. We aimed to evaluate nerve safety, pain relief, and patient satisfaction in a series of patients treated with the iO-Flex shaver system (Amendia, Inc., Marietta, Georgia).

Methods: Thirty-one consecutive patients with lumbar foraminal stenosis underwent foraminal decompression using the flexible microblade shaver system at 62 neuroforamina. The shavers were inserted into each foramen using an open hemilaminotomy and fluoroscopic guidance. Nerve mapping via mechanomyography (MMG) was used to ensure nerve safety. Perioperative charts were reviewed to find the incidence of neurologic complications and to quantify pain relief. Average office-based follow-up was 5.3 months. A 3-item questionnaire was administered to assess patient satisfaction during late follow-up, which occurred at an average of 21 months.

Results: No planned iO-Flex foraminotomies were aborted. Neurologic complications included transient dysesthetic pain in 1 patient $(3.2 \%, n=31)$, and transient numbness in 3 patients $(9.7 \%, n=31)$. There were no motor deficits. The composite nerve complication rate was $12.7 \%$. Preoperative visual analog scale scores decreased from a mean of $7.1(n=31$, standard deviation [SD] 2.0) to a mean of $3.5(n=30, \mathrm{SD} 2.5)$. If asked to repeat their decision to do surgery, $81 \%$ of patients would redo the procedure. The rate of patient dissatisfaction was $19 \%$.

Conclusions: Decompression of lumbar foramina using the flexible shaver system and MMG nerve mapping is safe and effective, although the short-term sensory complication with this technique may be higher than previously reported. Patient satisfaction with iO-Flex foraminotomy is comparable to reported satisfaction outcomes for traditional lumbar decompression.
\end{abstract}

Level of Evidence: 4.

Lumbar Spine

Keywords: iO-Flex, flexible shaver system, foraminotomy, lumbar foraminal stenosis, lumbar decompression

\section{INTRODUCTION}

Lateral foraminal stenosis is an important cause of lumbar radiculopathy and accounts for $8 \%$ to $11 \%$ of cases of said disease. ${ }^{1}$ There are multiple etiologies of lateral foraminal stenosis. These include superior facet hypertrophy, hypertrophied ligamentum flavum, laminar osteophytes, hypertrophied synovium or facet cysts, loss of disc height, and lateral disc herniation, among others. ${ }^{1-3}$ The importance of this pathology as a pain generator is evidenced by studies that implicate incomplete foraminal decompression in $25 \%$ to $29 \%$ of failed back syndrome cases. $^{4}$
A number of techniques exist for foraminal decompression including traditional, endoscopic, and open posterolateral techniques. ${ }^{5,6}$ A traditional decompression may create instability in cases of far lateral stenosis, necessitating a fusion. Another option for decompression is a facet-sparing foraminotomy technique using the iO-Flex flexible shaver system (Amendia, Inc., Marietta, Georgia). ${ }^{7,8}$ The literature on the safety and effectiveness of this technique is limited to 2 industry-sponsored studies. $^{7,8}$ Nevertheless, many have incorporated this technology into clinical practice. We aim to share our early experience using the iO-Flex flexible shaver system in combination with a mechanomyography (MMG) nerve mapping system (Sen- 


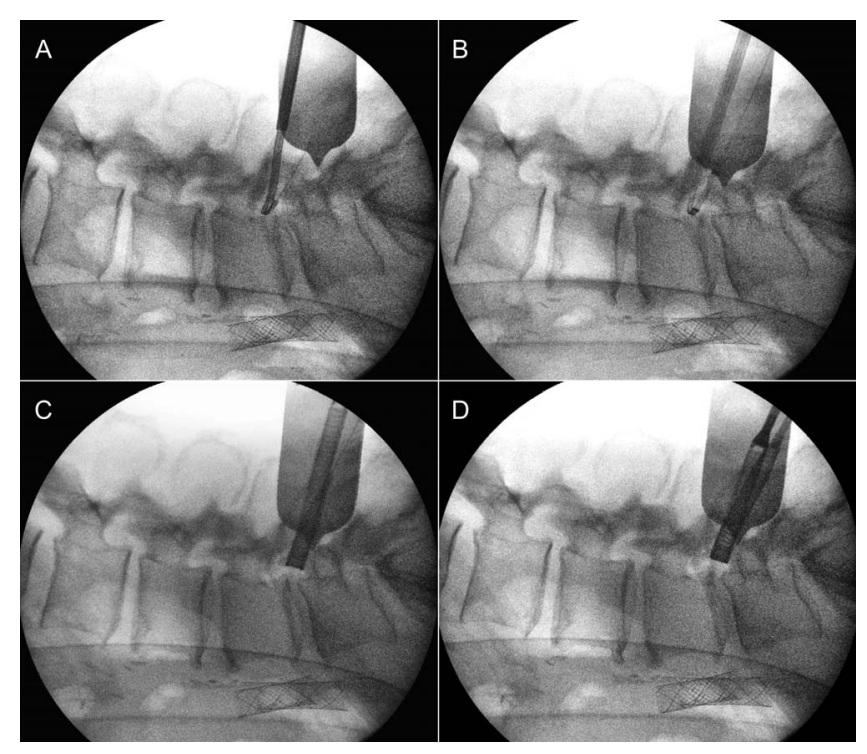

Figure 1. Intraoperative fluoroscopic imaging of (A) guidewire passage, (B) insertion of Neuro Check device, (C) foraminal height before foraminotomy, and (D) foraminal height after foraminotomy.

tioMMG; Sentio, LLC, Wixom, Michigan), focusing on the incidence of nerve complications, as well as pain relief and patient satisfaction.

\section{MATERIALS AND METHODS}

With institutional review board approval, we conducted a retrospective study of 31 consecutive patients, who underwent lumbar neuroforaminal decompression using the iO-Flex System at a total of 62 neuroforaminal levels between November 2011 and October 2015. Subjects were identified through a comprehensive chart review, based on Current Procedural Terminology code 63030, laminotomy/hemilaminotomy with nerve root decompression. Collected demographic data included age, gender, and body mass index. All subjects were 18 years of age or older, and no cases were excluded. Of the 31 procedures, 7 included revision decompressions, 1 of which was also a revision fusion.

\section{Operative Technique}

Surgery was performed through a posterior midline approach. A small hemilaminotomy incision was used for isolated decompressions, and an open approach was used for the 1 revision fusion case. Although a single interlaminar window can be used to access multiple adjacent foramina, ${ }^{8}$ we used a single hemilaminotomy to expose each foramen. The ligamentum flavum was removed, and the dura was visualized directly. A cannulated probe was inserted through the laminar window and through the corresponding lateral recess and neuroforamen, just superior to the caudal pedicle. The system's guidewire was deployed through a cannulated probe, the probe was withdrawn, and the positioning of the guidewire was scrutinized with fluoroscopy (Figure 1A). A dual-electrode Neuro Check device (Amendia, Inc.) (nerve stimulator) and MMG (SentioMMG) were employed to map the exiting nerve (Figure 1B). The Neuro Check device was used in monopolar mode for all cases. Once the Neuro Check device demonstrated a current differential of greater than or equal to $2 \mathrm{~mA}$ between the near and far electrodes, indicating that the nerve was deep to our instruments, a flexible microblade shaver was passed through the foramen (Figure 1C). Shaver size was selected based on the size of the target foramen on fluoroscopy. Decompression of the lateral recess and foramen was achieved with gentle upward tension and short bimanual reciprocations. Adequacy of decompression was assessed first by checking for a qualitative change in foraminal height on lateral fluoroscopy (Figure 1D), and then by palpation using a Woodson elevator. The senior author performed all cases.

\section{Outcomes}

The primary outcome of this study was the incidence of neurologic complications in the immediate postoperative period. Preoperative and postoperative surgical assessments were reviewed, and any new motor or sensory changes were identified. We also assessed early postoperative pain relief and patient satisfaction at late follow-up. We measured pain relief by comparing immediate preoperative visual analog scale (VAS) scores with VAS scores at the second postoperative visit. When pain was reported as mild, moderate, or high, numerical values of 1,4 , or 7 were respectively assigned. Patient satisfaction was assessed using a 3-item questionnaire (Table 1), which was administered via telephone during late follow-up. The incidence of repeat lumbar spine surgery at late follow-up was used as a marker of patient satisfaction in this survey.

\section{Statistical Methods}

All continuous data were described using means, standard deviations (SDs), medians, minimums, and maximums while categorical data are described using counts and percentages. The difference in VAS scores was calculated by subtracting preoper- 
Table 1. Late follow-up survey questions and responses. Of the 21 respondents, $66.7 \%$ were satisfied with their care, and $80.9 \%$ indicated that they would repeat their surgery given their outcome.

\begin{tabular}{lc}
\hline Questions and Responses & Result \\
\hline Q1: Are you satisfied with your medical care? & \\
Very dissatisfied & $1(4.8 \%)$ \\
Somewhat dissatisfied & $3(14.3 \%)$ \\
Neither & $3(14.3 \%)$ \\
Somewhat satisfied & $0(0.0 \%)$ \\
Very satisfied & $14(66.7 \%)$ \\
Q2: Would you repeat the procedure? & $4(19.1 \%)$ \\
No & $17(80.9 \%)$ \\
Yes & $17(80.9 \%)$ \\
Q3: Have you had other surgeries since the one in question? \\
No & $4(19.1 \%)$ \\
Yes & \\
\hline
\end{tabular}

ative VAS from postoperative VAS scores. This difference was compared between subgroups using Wilcoxon rank-sum tests for 2-level subgroups and using Kruskal-Wallis tests for subgroups with 3 or more levels. Categorical responses were compared between groups using Fisher's exact tests due to small cell counts. Statistical significance was set at $P<.05$. All analyses were performed using SAS 9.4 (SAS Institute, Inc., Cary, North Carolina).

\section{RESULTS}

\section{Patient Population}

There were 31 consecutive patients in our series. Mean age was 54.6 years $(\mathrm{n}=31$, SD 13.1). Mean body mass index was $32.1 \mathrm{~kg} / \mathrm{m}^{2}(\mathrm{n}=31$, SD 6.2$)$. There were 12 women $(\mathrm{n}=31,38.7 \%)$ and 19 men $(\mathrm{n}=31,61.3 \%)$. Twenty-four $(\mathrm{n}=31,77.4 \%)$ cases were first time surgeries, and $7(n=31,22.6 \%)$ cases were revision decompressions. Surgeries performed included $14(\mathrm{n}=30,46.7 \%)$ hemilaminotomy foraminotomy procedures, $15(\mathrm{n}=30,50.0 \%)$ hemilaminotomy foraminotomy with discectomy procedures, and $1(\mathrm{n}=30,3.3 \%)$ hemilaminotomy foraminotomy with fusion procedure.

Average total follow-up was 15 months. Average office follow-up was 5.3 months while late phone interview occurred at an average of 21 months. Only

Table 2. Nerve complications.

\begin{tabular}{lcc}
\hline Response & N & Result \\
\hline Complications & & \\
$\quad$ None & 31 & $27(87.1 \%)$ \\
$\quad$ Hypersensitivity & & $1(3.2 \%)$ \\
$\quad$ Numbness & & $3(9.7 \%)$ \\
Complications (binary) & 31 & $27(87.1 \%)$ \\
$\quad$ None & & $4(12.9 \%)$ \\
Hypersensitivity/numbness & & \\
\hline
\end{tabular}

Table 3. Preoperative and postoperative VAS scores.

\begin{tabular}{lccc}
\hline & & \multicolumn{2}{c}{ Result } \\
\cline { 3 - 4 } Variable & N & Mean (SD) & $\begin{array}{c}\text { Median (Minimum, } \\
\text { Maximum) }\end{array}$ \\
\hline Preoperative VAS & 31 & $7.1(2.0)$ & $7(3,10)$ \\
Postoperative VAS & 30 & $3.5(2.5)$ & $3(0,10)$ \\
\hline
\end{tabular}

Abbreviation: VAS, visual analog scale.

21 of our patients $(n=31,68 \%)$ were available for late phone interview.

\section{Nerve Mapping and Neurologic Complications}

The iO-Flex flexible shaver system was employed at each planned level. A mean of 2 levels $(n=31$, SD 1.1) were decompressed in each case. The average stimulation current for the deep electrode was $5.1 \mathrm{~mA}(\mathrm{n}=46, \mathrm{SD} 3.1)$. The average $\mathrm{MMG}$ stimulation current differential between the deep and superficial electrodes during nerve mapping was $7.2 \mathrm{~mA}(\mathrm{n}=56, \mathrm{SD} 2.7)$. Average percent current differential was $332 \%(n=46$, SD 2.3$)$.

There were no postoperative motor deficits. Three patients $(\mathrm{n}=31,9.7 \%)$ complained of transient numbness postoperatively, while 1 patient $(\mathrm{n}=31,3.2 \%)$ complained of transient hypersensitivity pain (Table 2). The composite nerve complication rate was $12.9 \%$.

\section{Pain Relief}

Regarding pain relief, the mean preoperative VAS score was $7.1 \quad(\mathrm{n}=31$, SD 2.0); mean postoperative VAS score was $3.5(\mathrm{n}=30$, SD 2.5) (Table 3). Comparing patients who underwent foraminotomy alone versus those who underwent foraminotomy with discectomy, the mean VAS score differences were $3.9(\mathrm{n}=13)$ and 3.4 $(\mathrm{n}=17)$, respectively $(P=.7)$ (Table 4$)$. Mean VAS differences between first-time surgeries and

Table 4. VAS score comparisons by preoperative revision status and procedure type.

\begin{tabular}{llcc}
\hline Variable & \multicolumn{1}{c}{ Response } & $\begin{array}{c}\text { Change in VAS, } \\
\text { Mean (SD) }\end{array}$ & $\boldsymbol{P}$ Value \\
\hline Revision Status & No $(\mathrm{N}=24)$ & $-3.8(3.0)$ & .774 \\
Procedure Type & $\begin{array}{l}\text { Yes }(\mathrm{N}=6) \\
\text { Hemilaminotomy } \\
\text { Foraminoplasty } \\
(\mathrm{N}=13)\end{array}$ & $-3.2(2.9)$ & .757 \\
& HF+Discectomy & & \\
& $(\mathrm{N}=15)$ & $-3.4(2.7)$ & \\
& $\mathrm{HF}+$ Fusion $(\mathrm{N}=1)$ & $-2.0(-)$ & \\
\hline
\end{tabular}

Abbreviation: VAS, visual analog scale. 
Table 5. Itemized responses to satisfaction questionnaire by preoperative revision status.

\begin{tabular}{|c|c|c|c|}
\hline & $\begin{array}{c}\text { Revision }=\text { No } \\
(N=15)\end{array}$ & $\begin{array}{c}\text { Revision }=\text { Yes } \\
(\mathbf{N}=\mathbf{6})\end{array}$ & $P$ Value \\
\hline \multicolumn{4}{|c|}{ Q1: Are you satisfied with your medical care? } \\
\hline Very dissatisfied & 0 & $1(16.7 \%)$ & .155 \\
\hline Neither satisfied nor dissatisfied & $3(20.0 \%)$ & 0 & \\
\hline Somewhat satisfied & $3(20.0 \%)$ & 0 & \\
\hline Very satisfied & $9(60.0 \%)$ & $5(83.3 \%)$ & \\
\hline \multicolumn{4}{|l|}{ Q2: Would you repeat the procedure? } \\
\hline No & $4(26.7 \%)$ & 0 & .281 \\
\hline Yes & $11(73.3 \%)$ & $6(100.0 \%)$ & \\
\hline \multicolumn{4}{|c|}{ Q3: Have you had other surgeries since the one in question? } \\
\hline No & $12(80.0 \%)$ & $5(83.3 \%)$ & $>.999$ \\
\hline Yes & $3(20.0 \%)$ & $1(16.7 \%)$ & \\
\hline
\end{tabular}

revision cases were $3.8(\mathrm{n}=24)$ and $3.2(\mathrm{n}=6)$, respectively $(P=.774)$ (Table 4$)$.

\section{Patient Self-Rated Outcome and Reoperation Rate}

When patients were asked at late follow-up about their satisfaction with the overall medical care, $66.7 \%$ $(\mathrm{n}=21)$ were very satisfied, $0 \%$ were somewhat satisfied, $14.3 \%(\mathrm{n}=21)$ were neither satisfied nor dissatisfied, and 19\% $(\mathrm{n}=21)$ were dissatisfied (Table 1). When asked whether they would repeat their decision to undergo surgery given their outcome, $80.9 \%(n=21)$ responded that they would still have had surgery, while $19.1 \%(\mathrm{n}=21)$ would not (Table 1). Finally, when queried at late follow-up about whether they had undergone repeat lumbar spine surgery after iO-Flex foraminotomy, 19.1\% $(\mathrm{n}=21)$ responded "yes" (Table 1). These were for revision decompressions, 3 with fusion and 1 without fusion.

There were no significant differences in the satisfaction questionnaire responses between firsttime and revision surgeries (Table 5). Procedure type-foraminotomy versus foraminotomy with discectomy-did not affect patient satisfaction $(P=.37)$, the incidence of repeat surgery $(P=.27)$, or the hypothetical repeat decision on consenting to surgery $(P=1.0)$.

\section{DISCUSSION}

Incomplete foraminal decompression is still implicated in failed back syndrome. ${ }^{1,3,4}$ Accordingly, surgeons continue to consider instrument options and related surgical techniques for spinal decompression. Paralleling this focus is the concern for facet destabilization, which can occur with an aggressive traditional foraminotomy, or partial facetectomy. The iO-Flex shaver system is designed to preserve the facet joint and thus limit potential for iatrogenic instability. ${ }^{8}$ Lauryssen et $\mathrm{al}^{8}$ performed a randomized comparative cadaveric study using computed tomography and independent imaging quantitative analysis. They showed that the flexible shaver thinned down the inferior articular process of a neuroforamen and widened the foramen while preserving the facet. ${ }^{8}$ Foraminotomy with the iOFlex device widened the foramen and lateral recesses significantly more than the traditional decompression in stenotic foramina. Furthermore, the shaver system removed less bone from the pars interarticularis and facet joint. Thus, there is potential that foraminotomy via the flexible shaver system can allow complete decompression while avoiding destabilization and the need for fusion in some patients. ${ }^{9}$

When performing a foraminotomy using the flexible shaver device, the bone-cutting instrument spans the entire foramen and wraps around its roof. Appropriately, there is concern that a nerve root could be trapped between the shaver and posterior elements and be injured. Dickinson et $\mathrm{al}^{10}$ assessed the incidence of nerve injury with this technique in combination with electromyographic nerve monitoring. They reported a $3.4 \%$ incidence of nerve complications including "paresthetic" foot pain $(\mathrm{n}=59,1.7 \%)$, worsened sciatic pain, and weakness of the decompressed nerve $(\mathrm{n}=59,1.7 \%)$. Of note in the latter case, the flexible shaver system was abandoned for a traditional decompression due to poor Neuro Check signals.

We obtained a higher overall nerve complication rate than Dickinson et $\mathrm{al}^{10}$ using the iO-Flex ${ }^{\mathrm{ru}}$ foraminotomy technique and MMG nerve monitoring, but the complications were mostly minor transient sensory changes. We had 1 case of postoperative hypersensitivity pain, or dysesthesia $(3.2 \%, \mathrm{n}=31)$; postoperative numbness was $9.7 \%$ $(\mathrm{n}=31)$; and our composite nerve complication rate was $12.9 \%$. Attention to the trajectory of instruments in the neuroforamen, ${ }^{11}$ as well as maintaining a flexed 
patient posture during surgery may prevent some of these events. Previous reports have shown the rate of the dysesthesias after endoscopic foraminal decompression to be $3.5 \%$ to $6.1 \%,{ }^{12,13}$ while the rate of dysesthesias after open far lateral decompression is $6 \%$ to $24 \%{ }^{14,15}$ Dysesthetic pain symptoms typically resolve with nonsteroidal anti-inflammatory drug, or rarely, dorsal root ganglion blockade. ${ }^{14,16}$ It is unclear whether previous studies counted numbness among their dysesthesia complications, but increased numbness after surgery is not uncommon. ${ }^{17}$

Neural mapping using stimulated electromyography has recently become a popular nerve injury avoidance technique, particularly during lateral lumbar interbody fusion procedures. ${ }^{18-20}$ Neural mapping is also advocated with the iO-Flex foraminotomy system. ${ }^{10} \mathrm{MMG}$ is an alternative to electromyography for detection of muscle activation after electrical stimulation of nerves within or near the operative field. Rather than detecting an electrical response, it detects the mechanical response in the muscle. ${ }^{21}$ Unlike electromyography, in which the signal is often contaminated by electrical noise and difficult to analyze, ${ }^{22,23} \mathrm{MMG}$ offers a clear signal that is devoid of background noise, thus allowing detection of muscle responses from very low electrical stimulation currents. ${ }^{21,22}$ The SentioMMG system, which we used, has the added benefits of being a surgeon-driven nerve monitoring system and of not requiring neuromonitoring personnel. In our study, no attempts at iO-Flex foraminotomy were aborted. Confidence in nerve safety was given by large differentials between the MMG responses to electrical stimulation by the deep and superficial electrodes of the Neuro Check. The average percent differential between the electrodes, which are a few millimeters apart, was $332 \%$. The average difference in stimulation currents between the electrodes was $7.2 \mathrm{~mA}$. This large differential between superior and inferior surfaces of the Neuro Check device makes it clear where the nerve is located. Of note, nerve mapping only mitigates neurologic injury; vascular structures within the neuroforamen are still at risk. Injury to vascular structures and resultant bleeding may be a cause of sensory complications due to irritation of the dorsal root ganglion.

Overall patient satisfaction was high: $81 \%$ of patients would repeat their decision to have surgery, and only $19 \%$ were dissatisfied with their overall care. Nineteen percent of patients underwent a subsequent operation. These outcomes are compa- rable with previous reports on overall patient satisfaction after lumbar decompression, which is $70 \%$ to $80 \% .^{24,25}$

Our study was limited by its retrospective nature and its small sample size. The percentage of patients available for late follow-up interview was only $68 \%$. Thus, loss to follow-up bias may have affected our results. Future studies should include a focus on nerve injury mitigation. Is foraminal height loss a risk factor for dysesthesias, and can increased lumbar flexion posture during surgery decrease dysesthesias? Future prospective studies should also compare differences in clinical improvement and foraminal and lateral recess radiographic patency after traditional foraminotomy versus iO-Flex foraminotomy for lumbar radiculopathy. Additionally, there is potential to study outcomes of flexible shaver foraminotomy for patients with grade 1 degenerative spondylolisthesis who may not be fusion candidates. Finally, there has been no analysis on the added cost and benefit of using the iO-Flex and neuromonitoring devices to patient outcome compared to a traditional foraminotomy.

\section{CONCLUSION}

Foraminotomy via the iO-Flex flexible shaver device and $M M G$ nerve mapping safely and effectively decompresses the foramen and lateral recess. Patient satisfaction after decompression using this device is moderate to high and is comparable to previously reported satisfaction scores after more traditional techniques. Although there is no permanent neurologic deficit associated with this technique, postoperative dysesthesias remain a concern with iO-Flex foraminotomy, as it does with all far lateral decompressions.

\section{ACKNOWLEDGMENTS}

The senior author reports personal fees from LDR Spine, personal fees and nonfinancial support from DePuy, nonfinancial support from Stryker, grants, personal fees and nonfinancial support from MTF, nonfinancial support from AAOS, grants from BCBSM, and grants from William Davidson Foundation, outside the submitted work; in addition, the senior author has patents 8343079, $8343065,8517954,8855822,9992679,8892259$, 8942797, 9039630, 8983593, 8979767, and 9084550 licensed to Sentio, LLC. All other authors have nothing to disclose. 


\section{REFERENCES}

1. Jenis LG, An HS. Spine update. Lumbar foraminal stenosis. Spine (Phila Pa 1976). 2000;25(3):389-394.

2. Lee CK, Rauschning W, Glenn W. Lateral lumbar spinal canal stenosis: classification, pathologic anatomy and surgical decompression. Spine (Phila Pa 1976). 1988;13(3):313320 .

3. Macnab I. Negative disc exploration. An analysis of the causes of nerve-root involvement in sixty-eight patients. $J$ Bone Joint Surg Am. 1971;53(5):891-903.

4. Kim CW, Siemionow K, Anderson DG, Phillips FM. The current state of minimally invasive spine surgery. Instructional Course Lectures. 2011;60:353-370.

5. Ahn Y, Lee SH, Park WM, Lee HY. Posterolateral percutaneous endoscopic lumbar foraminotomy for L5-S1 foraminal or lateral exit zone stenosis. Technical note. $J$ Neurosurg. 2003;99(3 Suppl):320-323.

6. Kang K, Rodriguez-Olaverri JC, Schwab F, Hashem J, Razi A, Farcy JP. Partial facetectomy for lumbar foraminal stenosis. Adv Orthop. 2014;2014:534658.

7. Lauryssen C. Technical advances in minimally invasive surgery: direct decompression for lumbar spinal stenosis. Spine (Phila Pa 1976). 2010;35(26 Suppl):S287-S293.

8. Lauryssen C, Berven S, Mimran R, et al. Facet-sparing lumbar decompression with a minimally invasive flexible MicroBlade Shaver(R) versus traditional decompression: quantitative radiographic assessment. Clinical Interv Aging. 2012;7:257-266.

9. Sandhu F. Spinal surgery: ask Dr. Faheem Sandhu [video file]. https://youtu.be/WLqx_hh9eE8. Accessed April 17, 2018.

10. Dickinson LD, Phelps J, Summa CD, et al. Facetsparing decompression with a minimally invasive flexible microblade shaver: a prospective operative analysis. J Spinal Disord Tech. 2013;26(8):427-436.

11. Osorio JA, Saigal R, Chou D. Neurologic complications of common spine operations. Benzel's Spine Surgery: Techniques, Complication Avoidance, and Management. 4th ed. Philadelphia, PA: Elsevier Health Sciences; 2016.

12. Li ZZ, Hou SX, Shang WL, Cao Z, Zhao HL. Percutaneous lumbar foraminoplasty and percutaneous endoscopic lumbar decompression for lateral recess stenosis through transforaminal approach: technique notes and 2 years followup. Clin Neurol Neurosurg. 2016;143:90-94.

13. Ahn Y, Oh HK, Kim H, Lee SH, Lee HN. Percutaneous endoscopic lumbar foraminotomy: an advanced surgical technique and clinical outcomes. Neurosurgery. 2014;75(2):124-133.

14. Darden BV 2nd, Wade JF, Alexander R, Wood KE, Rhyne AL 3rd, Hicks JR. Far lateral disc herniations treated by microscopic fragment excision. Techniques and results. Spine (Phila Pa 1976). 1995;20(13):1500-1505.

15. Baba H, Uchida K, Maezawa Y, Furusawa N, Okumura Y, Imura S. Microsurgical nerve root canal widening without fusion for lumbosacral intervertebral foraminal stenosis: technical notes and early results. Spinal Cord. 1996;34(11):644-650.

16. Wang H, Zhou Y, Zhang Z. Postoperative dysesthesia in minimally invasive transforaminal lumbar interbody fusion: a report of five cases. Eur Spine J. 2016;25(5):1595-1600.

17. Donaldson WF 3rd, Star MJ, Thorne RP. Surgical treatment for the far lateral herniated lumbar disc. Spine. 1993;18(10):1263-1267.

18. Cheng I, Acosta F, Chang K, Pham M. Pointcounterpoint: the use of neuromonitoring in lateral transpsoas surgery. Spine (Phila Pa 1976). 2016;41(Suppl 8):S145-S151.

19. Uribe JS, Vale FL, Dakwar E. Electromyographic monitoring and its anatomical implications in minimally invasive spine surgery. Spine (Phila Pa 1976). 2010;35(26 Suppl):S368-S374.

20. Tohmeh AG, Rodgers WB, Peterson MD. Dynamically evoked, discrete-threshold electromyography in the extreme lateral interbody fusion approach. J Neurosurg Spine. 2011;14(1):31-37.

21. Wessell N, Khalil J, Zavatsky J, Ghacham W, Bartol S. Verification of nerve decompression using mechanomyography. Spine J. 2016;16(6):679-686.

22. Ibitoye MO, Hamzaid NA, Zuniga JM, Abdul Wahab AK. Mechanomyography and muscle function assessment: a review of current state and prospects. Clinical Biomech (Bristol, Avon). 2014;29(6):691-704.

23. Chowdhury RH, Reaz MB, Ali MA, Bakar AA, Chellappan K, Chang TG. Surface electromyography signal processing and classification techniques. Sensors (Basel). 2013;13(9):12431-12466.

24. den Boogert HF, Keers JC, Marinus Oterdoom DL, Kuijlen JM. Bilateral versus unilateral interlaminar approach for bilateral decompression in patients with single-level degenerative lumbar spinal stenosis: a multicenter retrospective study of 175 patients on postoperative pain, functional disability, and patient satisfaction. J Neurosurgery Spine. 2015;23(3):326-335.

25. Katz JN, Stucki G, Lipson SJ, Fossel AH, Grobler LJ, Weinstein JN. Predictors of surgical outcome in degenerative lumbar spinal stenosis. Spine (Phila Pa 1976). 1999;24(21):2229-2233.

Disclosures and COI: Stephen Bartol, MD, has a private investment in Sentio, LLC (20\%, paid directly to the author), and is an advisor to the Musculoskeletal Transplant Foundation (paid directly to the author and his institution). For the remaining authors, none were declared.

Corresponding Author: Morenikeji Ayodele Buraimoh, MD, Department of Orthopaedic Surgery, Henry Ford Health System, 2799 West Grand Blvd, CFP 642, Detroit, MI 48202. Phone: (313) 916-7520; Fax: (313) 916-0475; Email: aburaimoh@ gmail.com.

\section{Published 3 August 2018}

This manuscript is generously published free of charge by ISASS, the International Society for the Advancement of Spine Surgery. Copyright (C) 2018 ISASS. To see more or order reprints or permissions, see http://ijssurgery.com. 